\title{
Willingness to Vaccinate or Get Vaccinated with an Intradermal Seasonal Influenza Vaccine: a Survey of General Practitioners and the General Public in France and Germany
}

Robert Arnou · Matthias Frank . Thomas Hagel · Alice Prébet

Received: March 29, 2011 / Published online: May 20, 2011

(c) The Author(s) 2011. This article is published with open access at springerlink.com.

\section{ABSTRACT}

Introduction: The elderly are at high risk of severe seasonal influenza and influenza-related death. Annual vaccination can effectively prevent influenza and its complications, and is recommended in the elderly. In the present study, surveys were undertaken in France and Germany to determine whether INTANZA ${ }^{\circledR}$ (sanofi pasteur, Val-de-Reuil, France), the first intradermal influenza vaccine, administered using an innovative microneedle injection system, might influence physicians' likelihood of recommending influenza vaccination or the likelihood that the general public would seek influenza vaccination. Methods: Physicians

Robert Arnou

ALTI Clinical Research Network, 49000 Angers, France

Matthias Frank $(\bowtie)$

General Practice, Am Brurain 12, 76187, Karlsruhe,

Germany. Email: mb.frank@t-online.de

Thomas Hagel

GfK SE HealthCare, Nordwestring 101, 90419 Nürnberg, Germany

Alice Prébet sanofi pasteur MSD, 8 Rue Jonas Salk, 69367 Lyon Cedex 07, France
(France: $n=260$; Germany: $n=223$ ) and members of the general public aged $\geq 50$ years (France: $n=1706$; Germany: $n=1072$ ) completed online surveys. Details of the INTANZA delivery system, and a "product profile" based on the properties of INTANZA, were presented. Results: Most physicians and the general public found INTANZA and its microneedle injection system appealing. The main benefit of INTANZA, as perceived by physicians and the public, was the small needle size. Physicians also found the high immunogenicity compared with conventional intramuscular (IM) vaccines attractive. The majority of physicians believed that INTANZA would strongly help them to recommend vaccination to their unvaccinated patients (66\% to $91 \%$, depending upon patient characteristics); most (61\% to 78\%) would prefer to prescribe INTANZA rather than an IM vaccine. More than two-thirds of the unvaccinated general public would prefer INTANZA over IM vaccines, and the option of vaccination with INTANZA would encourage a large proportion of them to get vaccinated (60\% to $74 \%$ ), if it was recommended and they were given the choice. Physicians ( $\geq 82 \%$ ) agreed that INTANZA may help increase vaccination coverage rates. Conclusion: The results of these surveys indicate 
that the availability of INTANZA may encourage physicians to recommend influenza vaccination, and members of the general public to get vaccinated. INTANZA may help to improve seasonal influenza vaccination coverage rates.

Keywords: INTANZA; intradermal influenza vaccine; microneedle injection system; survey; vaccination coverage rate; willingness to vaccinate/get vaccinated

\section{INTRODUCTION}

Although seasonal influenza is sometimes perceived as a mild infection, it can cause severe illness and death. ${ }^{1}$ Indeed, it is estimated that deaths from seasonal influenza in the European Union (EU) range from 40,000 in a mild season, to 220,000 in a moderate-to-severe season. ${ }^{2}$ Approximately $90 \%$ of influenza-associated deaths occur in individuals aged $\geq 65$ years. ${ }^{3}$

Annual vaccination effectively prevents seasonal influenza and its complications. ${ }^{1}$ The World Health Organization (WHO) and the council for the EU have set targets for seasonal influenza vaccination coverage of $\geq 75 \%$ of the elderly (aged $\geq 65$ years) ${ }^{4,5}$ and those with chronic medical conditions. ${ }^{5}$ All Western European countries recommended influenza vaccination for these populations. ${ }^{6}$ In the $2007 / 8$ influenza season, vaccination coverage was slightly less than $65 \%$ in France and just over $60 \%$ in Germany among individuals for whom vaccination is recommended (those aged $\geq 65$ years in France and $\geq 60$ years in Germany). ${ }^{7}$ It is clear that further efforts are required to reach the $\geq 75 \%$ seasonal influenza vaccination coverage rate in these target groups. ${ }^{4,5}$ Consequently, it is important to evaluate any potential initiatives that may help to increase individuals' willingness to get vaccinated against influenza.
INTANZA $^{\circledR}$ (sanofi pasteur, Val-deReuil, France), the first intradermal (ID) influenza vaccine, is administered using an innovative, reliable, and easy-to-use microneedle injection. It provides high seroprotection by targeting the dermis, ${ }^{8,9}$ a highly immunogenic area. ${ }^{10,11}$ The dermis has a high density of lymphatic and blood capillary vessels, facilitating direct contact between administered antigens and the immune system. ${ }^{11}$ Hence, ID immunization triggers synergistic pathways thus amplifying the immune response. ${ }^{11}$

INTANZA is available in two doses to meet the seasonal vaccination requirements of different adult age groups. ${ }^{12}$ INTANZA 15 contains $15 \mu \mathrm{g}$ hemagglutinin (HA) for each of three influenza strains, and is intended for use in individuals aged $\geq 60$ years in whom influenza vaccinations are generally less effective. ${ }^{13}$ Clinical studies have shown that this vaccine provides antibody responses (and seroprotection) superior to those seen with conventional intramuscular (IM) vaccination in adults aged $\geq 60$ years. ${ }^{9}$ INTANZA 9, which contains $9 \mu \mathrm{g}$ HA for each of three influenza strains, is intended for use in adults aged $<60$ years, ${ }^{8,14}$ and has been shown to be as immunogenic as conventional IM seasonal influenza vaccine. ${ }^{8}$ Both formulations are well tolerated, and injection-site reactions are transient and generally mild..$^{8,9}$

The authors attempted to evaluate whether the availability of INTANZA and its microneedle injection system might influence physicians' likelihood of recommending influenza vaccination or the likelihood that the general public would seek influenza vaccination, thereby encouraging influenza vaccination uptake. Surveys of physicians, and of the general public aged $\geq 50$ years, were conducted in France and Germany. 


\section{MATERIALS AND METHODS}

\section{Survey}

Physicians and members of the general public in France and Germany were asked to complete an online questionnaire during July 15 to July 27 (physicians) and July 15 to August 15 (general public) of 2009. Participants responding 'I do not agree at all' to any of the following statements were considered as not being in favor of vaccination in general, or seasonal influenza vaccination specifically: vaccination against certain diseases is important for healthy living and the prevention of serious illnesses (all participants); I actively encourage flu vaccination (physicians); or I consider a flu vaccination useful for people aged $\geq 50$ (general public). These individuals were identified during the screening process and excluded from the analysis.

Details of the microneedle injection system by which INTANZA is delivered (Figure 1) and a "product profile" for a new ID seasonal influenza vaccine, described as product X (INTANZA), based on a summary of INTANZA 9 and INTANZA 15 summary of product characteristics and clinical trial data, ${ }^{8,9,15}$ were presented. The "product profile" was adapted for the general public and a combination of the characteristics of INTANZA 9 and INTANZA 15 was presented. Participants were informed that "product $X$ " would be recommended and reimbursed in the same way as conventional IM seasonal influenza vaccines.

Three assessments were undertaken based on the information presented: the general impressions and appeal of INTANZA; preference between ID administration with INTANZA and conventional IM influenza vaccination; and the willingness of physicians to vaccinate new patients with INTANZA for the next influenza season, or willingness of members of the general public to be vaccinated with INTANZA for the next influenza season. Appeal was assessed using a five-point scale: "very appealing," "appealing," "not appealing," "not appealing at all," and "don't know". Physicians' belief about whether INTANZA

Figure 1. The INTANZA microneedle injection system compared with the conventional intramuscular influenza vaccine delivery method.

INTANZA $^{\circledR}$ microneedle injection system
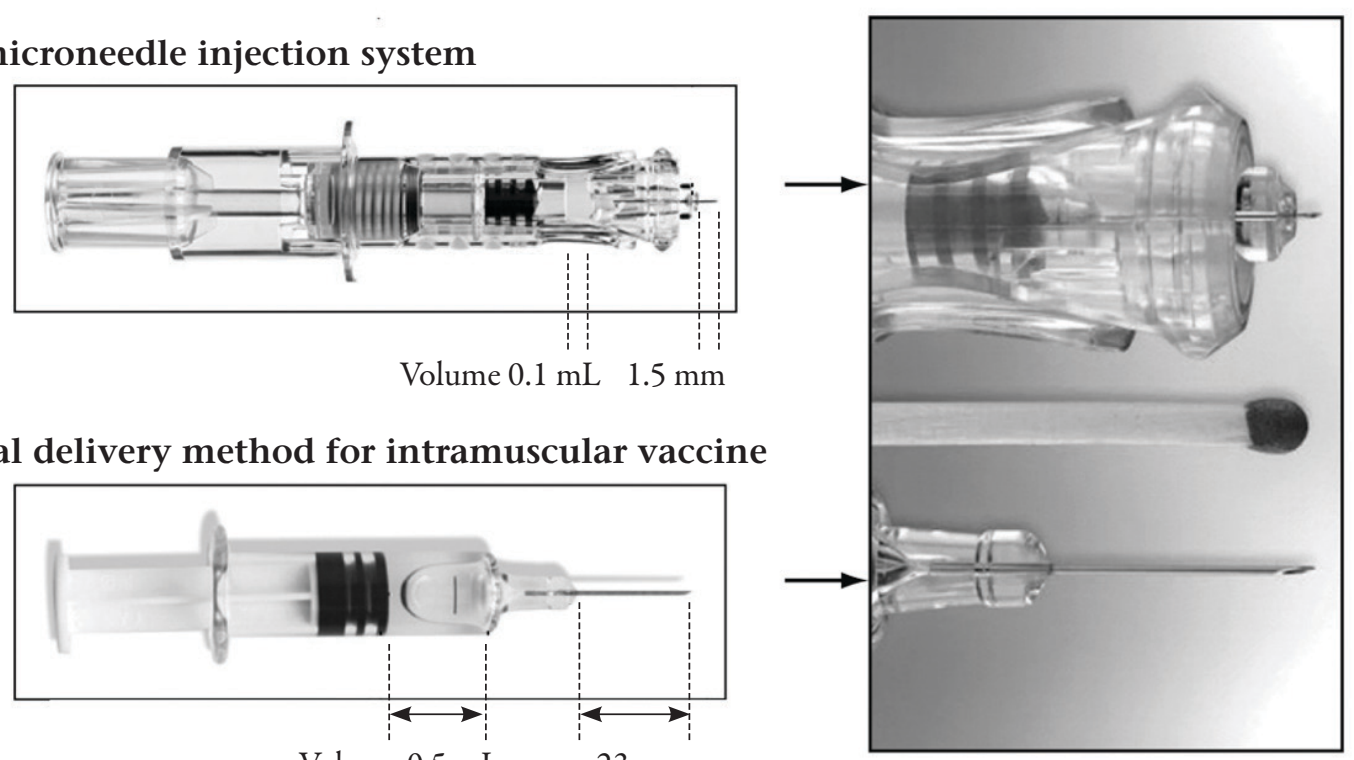

Conventional delivery method for intramuscular vaccine

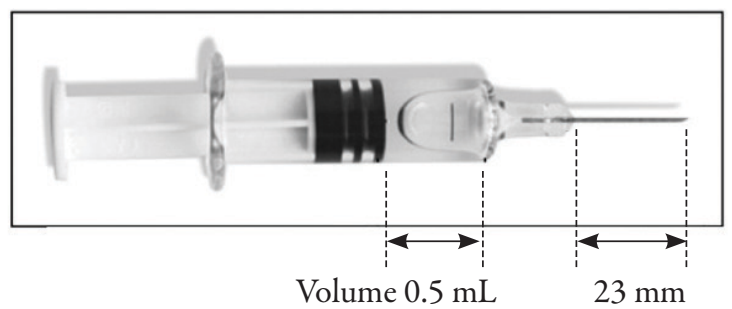


would help them recommend seasonal influenza vaccination was measured on a five-point scale: "very strongly," "strongly," "not strongly," "not strongly at all," and "don't know". A five-point scale was also used to assess whether physicians were likely to prescribe INTANZA to their patients: "very likely," "likely," "not likely," "not likely at all," and "don't know".

\section{Participants}

\section{Physicians}

Physicians were recruited from a European panel of family physicians with $>15,000$ members. Those with between 3 and 35 years' experience and who administered and/ or prescribed seasonal influenza vaccines were eligible to participate in the survey if $\geq 20 \%$ of their patients were $>60$ years of age. Representativeness among physicians was achieved by applying specific quotas on age, gender, and regional spread.

\section{General Public}

Members of the general public were recruited from a consumer panel with 25,000 members in France and 27,000 members in Germany. Individuals aged 50 to 69 years were eligible to participate in the survey in France, and those aged 50 to 65 years were eligible to participate in Germany. Members of the general public were invited to participate in the survey and then made the decision to complete the survey on-line, thus implying their consent. Quotas on gender, age, region, social class (France), or monthly household income (Germany) were applied to obtain representative samples of the general public in France and Germany, referred to herein as the "average population".

Additional samples were recruited for those aged $\geq 60$ years in France and Germany to ensure there were sufficient sample sizes for those groups covered by the age-based seasonal influenza recommendations in each country.

\section{RESULTS}

\section{Study Populations}

A representative sample of physicians from France ( $n=260)$ and Germany ( $n=223$ ) completed the online survey. Of those participating, $45 \%$ of the French physicians and $40 \%$ of the German physicians practiced in towns with $<20,000$ inhabitants.

A total of 7150 members of the general public were invited to participate in the survey. Of these, $76.79 \%$ accepted the invitation and $50.60 \%$ completed the online questionnaire. In total, 1706 members of the general public in France and 1072 members of the general public in Germany completed the survey. Distribution data for members of the general public who participated can be found in Table 1 .

\section{Physicians}

\section{Appeal, Preference, and Likelihood of Prescribing INTANZA}

A very high proportion of physicians rated the characteristics of both INTANZA 9 and INTANZA 15 with its microneedle injection system as appealing ("very appealing" plus "appealing"). INTANZA 9 appealed to $87 \%$ of physicians in France and to $94 \%$ in Germany, and INTANZA 15 appealed to $94 \%$ and $91 \%$ of physicians in France and Germany, respectively.

The majority of physicians in both France and Germany believed that INTANZA 9 and INTANZA 15 would strongly help them to recommend seasonal influenza vaccination to unvaccinated patients (ie, those who were not vaccinated for the previous influenza season), 
particularly those averse to injections (Figure 2). The majority of physicians would also prefer to prescribe INTANZA over a conventional IM influenza vaccine. In France and Germany, respectively, INTANZA 9 was preferred by $73 \%$ and $61 \%$ of physicians whilst $78 \%$ and $63 \%$ of physicians preferred to prescribe INTANZA 15 versus conventional IM therapy.

Almost all physicians stated that they were likely (ie, "very likely" plus "likely") to prescribe INTANZA 15 to those patients covered by the national age-based recommendations, and those averse to needles (Figure 3). Physicians were also likely to prescribe INTANZA 9 to patients aged 18 to 59 years with and without risk factors, and to those averse to needles (Figure 3).

\section{Benefits of INTANZA}

Physicians perceived the main benefits of INTANZA to be its immunogenicity and seroprotection rates compared with conventional IM vaccines, in addition to the small needle size leading to a less painful or pain-free injection (Table 2). It should be noted that physicians' answers were spontaneous (ie, the physicians had the freedom to write their own responses), and the answers do not necessarily reflect the characteristics of INTANZA incorporated within the "product profile" presented.

Table 1. Distribution of the general public who participated in the survey.

\begin{tabular}{|c|c|c|}
\hline & France & Germany \\
\hline Total $(n)$ & 1706 & 1072 \\
\hline Average population* & 1203 & 802 \\
\hline Additional samples ${ }^{\dagger}$ & 503 & 270 \\
\hline Age range (years) & $50-69$ & $50-64$ \\
\hline $50-59$ & 736 & 587 \\
\hline $60-64$ & 510 & 485 \\
\hline Average population* & 243 & 215 \\
\hline Additional samples $^{\dagger}$ & 267 & 270 \\
\hline $65-69$ years & 460 & - \\
\hline Average population* & 224 & - \\
\hline Additional sample ${ }^{\dagger}$ & 236 & - \\
\hline \multicolumn{3}{|l|}{ Vaccinated/unvaccinated (average population)* } \\
\hline Vaccinated & 429 & 316 \\
\hline Unvaccinated $^{\ddagger}$ & 774 & 486 \\
\hline Covered by age-based recommendations and reimbursement ${ }^{\S}$ & 460 & 485 \\
\hline Vaccinated & 273 & 221 \\
\hline Unvaccinated $^{\ddagger}$ & 187 & 264 \\
\hline Working population" (average population)* & 979 & 587 \\
\hline Vaccinated & 293 & 215 \\
\hline Unvaccinated $^{\ddagger}$ & 686 & 372 \\
\hline
\end{tabular}

*Average population is the representative sample of people aged 50-69 years in France and aged 50-64 years in Germany, with the same age distribution among that age range as the general population.

†Additional representative samples were recruited to ensure sufficient sample sizes for those groups covered by the age-based recommendations.

¥Not vaccinated in the previous influenza season (2008/9).

$\S$ Seasonal influenza vaccination is recommended and reimbursed for those aged $\geq 65$ years in France and those aged $\geq 60$ years in Germany (average population and additional samples included for the valid age groups).

||Working age population in France: aged 50-64 years, Germany: aged 50-59 years (average population). 
Figure 2. Percentage of physicians who believe INTANZA would help them to strongly recommend* seasonal influenza vaccination to unvaccinated patients ${ }^{\dagger}$ (France: $n=260$; Germany: $n=223$ ). "Very strongly" or "strongly" on a five-point scale including "not strongly," "not strongly at all," and "I don't know." Those not vaccinated for the previous influenza season $(2008 / 9))^{\dagger}$

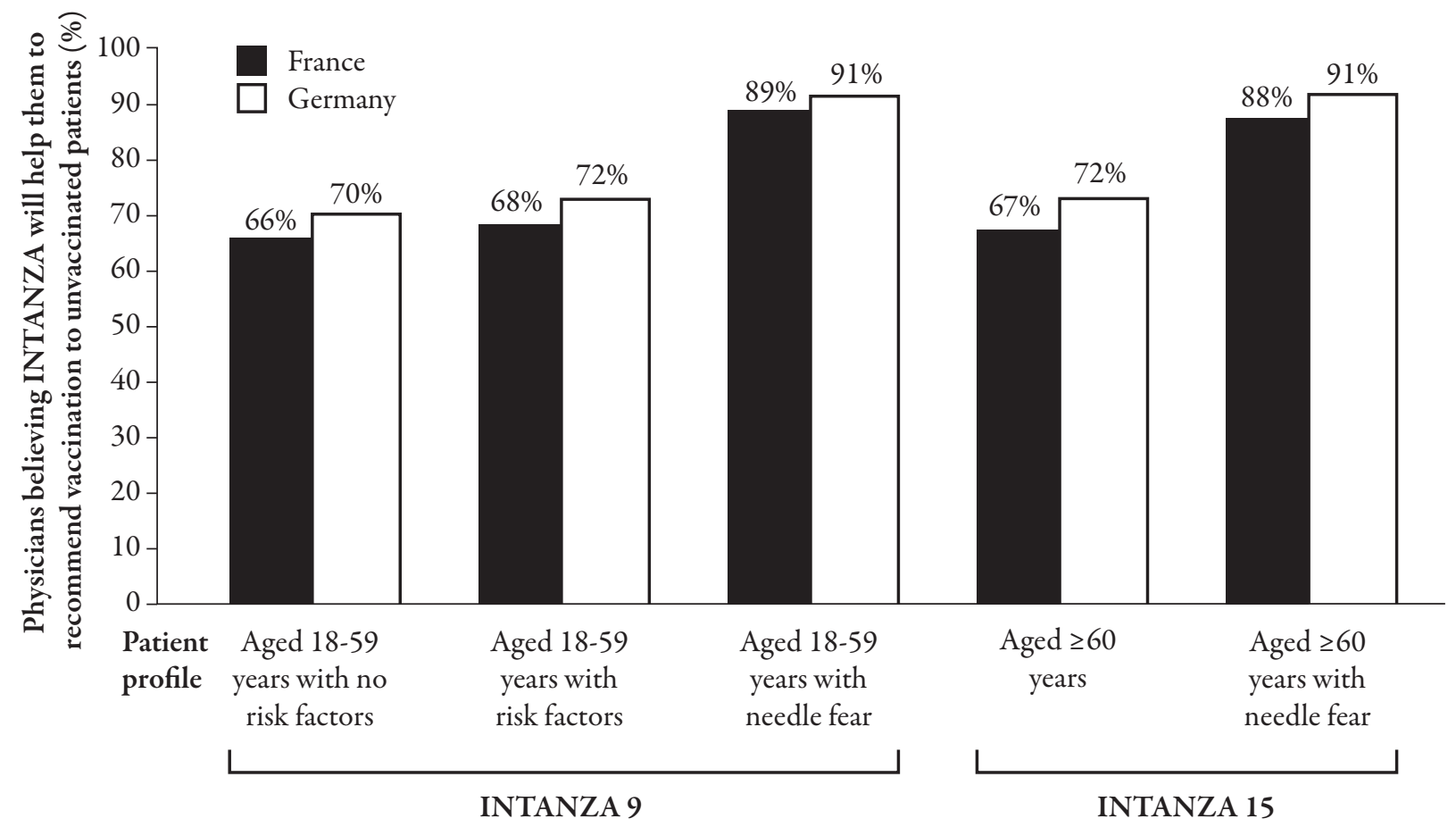

Figure 3. Percentage of physicians who were likely to prescribe* INTANZA to their patients (France: $n=260$; Germany: $n=223$ ). "Very likely" plus "likely" on a five-point scale that also included "not likely," "not likely at all", and "don't know"*

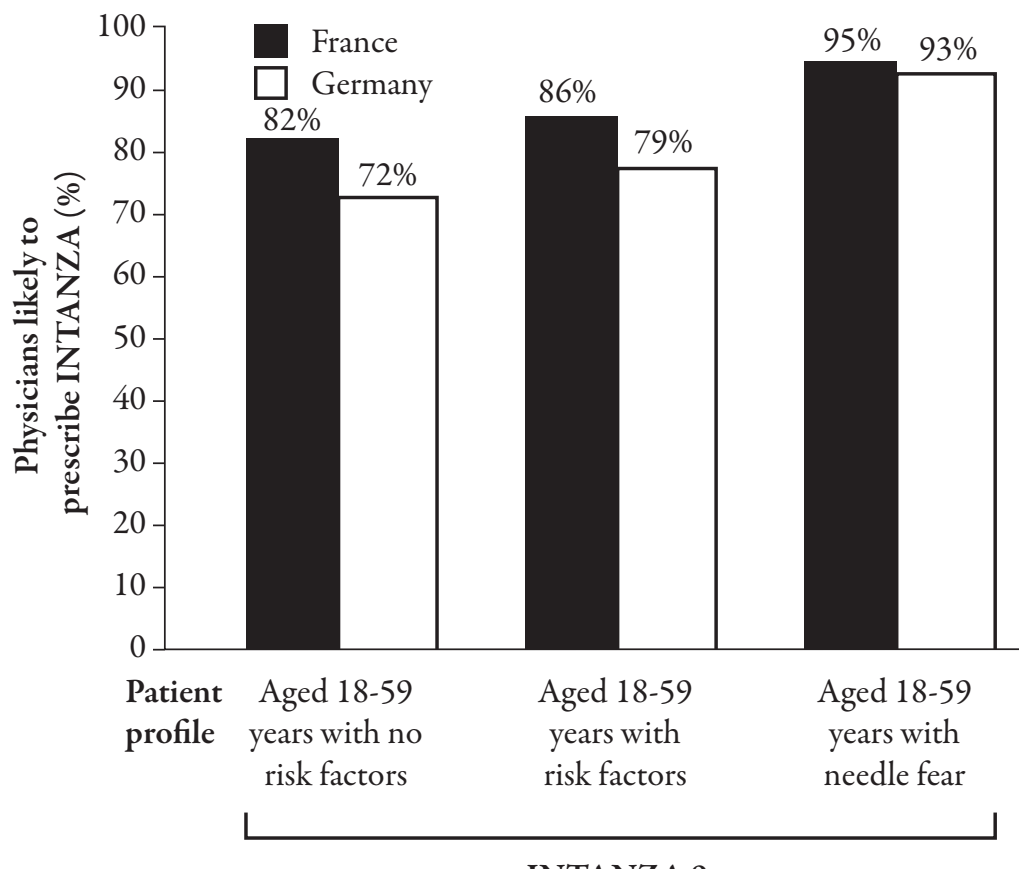

INTANZA 9

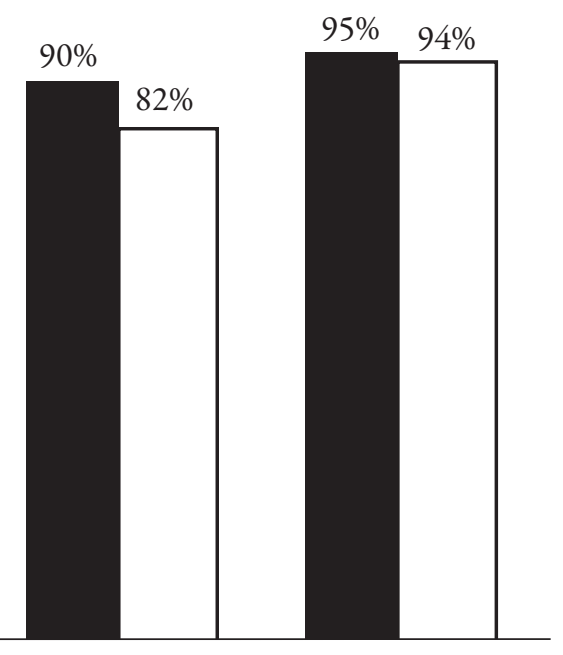

Aged $\geq 60$ years with needle fear 
The majority of physicians agreed with the statement, "This vaccine may help increase flu vaccination coverage rates as it will be well accepted by patients". In total, $82 \%$ of French physicians and $85 \%$ of German physicians agreed that INTANZA 9 could increase vaccination coverage rates, and $83 \%$ and $87 \%$ of French and German physicians, respectively, believed that INTANZA 15 could improve coverage rates.

\section{General Public}

The vast majority of the general public surveyed found INTANZA and its micro-injection system appealing ("very appealing" plus "appealing"). In France, 91\% of the average population found INTANZA appealing, along with 90\% of those covered by the age-based recommendations. Similarly, in Germany, $90 \%$ of the average population found INTANZA appealing, along with $91 \%$ of those covered by the age-based recommendations.
More than two in three members of the general public surveyed who were not vaccinated for the previous influenza season ("unvaccinated") would prefer to receive INTANZA over a conventional IM injection, if vaccination was recommended by their physician and they were given the choice (Figure 4). Indeed, a large proportion of the unvaccinated general public declared that the option of vaccination with INTANZA would encourage them to be vaccinated in the future, if it was recommended by their physician (Figure 4). Many of the unvaccinated public believed that the ID route of administration of INTANZA would reduce the degree of apprehension associated with annual influenza vaccination (France: 82\%; Germany: $60 \%$; average populations). Furthermore, in response to the question: "Do you think that the smaller needle size of the new seasonal flu vaccine would lower your fear of needles?" many participants' felt that the microneedle injection

Table 2. The benefits of INTANZA as perceived by family physicians and the general public (average population*). ${ }^{\dagger}$

\begin{tabular}{|c|c|c|c|c|c|c|}
\hline \multirow[b]{3}{*}{ Perceived benefits } & \multicolumn{4}{|c|}{ Family physicians } & \multirow{2}{*}{\multicolumn{2}{|c|}{$\begin{array}{l}\text { General public } \\
\text { INTANZA (\%) }\end{array}$}} \\
\hline & \multicolumn{2}{|c|}{ INTANZA $9(\%)$} & \multicolumn{2}{|c|}{ INTANZA $15(\%)$} & & \\
\hline & $\begin{array}{l}\text { France } \\
(n=260)\end{array}$ & $\begin{array}{l}\text { Germany } \\
(n=223)\end{array}$ & $\begin{array}{l}\text { France } \\
(n=260)\end{array}$ & $\begin{array}{l}\text { Germany } \\
(n=223)\end{array}$ & $\begin{array}{l}\text { France } \\
(n=1203)\end{array}$ & $\begin{array}{l}\text { Germany } \\
(n=802)\end{array}$ \\
\hline Small/short needle & 40 & 31 & 32 & 23 & 31 & 23 \\
\hline Small volume & 24 & 4 & 19 & 4 & 12 & 9 \\
\hline $\begin{array}{l}\text { High/higher immunogenicity (family physicians) } \\
\text { (general public) than intramuscular vaccination } \neq\end{array}$ & 17 & 13 & 31 & 23 & 14 & 12 \\
\hline Less painful/pain free & 17 & 14 & 17 & 10 & 17 & 10 \\
\hline More effective/better efficacy & 11 & 6 & 14 & 13 & 6 & 12 \\
\hline Easy to use/more practical & 10 & 12 & 10 & 10 & 8 & 6 \\
\hline $\begin{array}{l}\text { Intradermal administration (family physicians), } \mathrm{d} \\
\text { under the skin (general public) }\end{array}$ & 9 & 5 & 6 & 6 & 24 & 20 \\
\hline Well tolerated/fewer side effects & 7 & 5 & 9 & 5 & 22 & 34 \\
\hline Avoids fear of needles & 6 & 10 & 6 & 9 & 7 & 7 \\
\hline
\end{tabular}

*Average population is the representative sample of people aged 50-69 years in France and aged 50-64 years in Germany. †Answers were spontaneous (and are paraphrased) and do not necessarily reflect the characteristics of INTANZA incorporated within the "product profile"” presented.

キINTANZA 9 and 15 for family physicians, respectively. 
Figure 4. Percentage of the unvaccinated* general public who would prefer to receive INTANZA (compared with the conventional intramuscular vaccine), and who would be encouraged to get vaccinated ${ }^{\dagger}$ by the availability of INTANZA. Those who were not vaccinated for the previous influenza season (average population).* "Strongly encouraged" plus "encouraged" on a five-point scale that also included "not encouraged", "not encouraged at all", and "don't know". Those who were not vaccinated for the previous influenza season but in whom vaccination is recommended based on age (France: $\geq 65$ years; Germany $\geq 60$ years). ${ }^{\ddagger}$ Those aged $50-64$ years in France and those aged $50-59$ years in Germany. ${ }^{\S}$

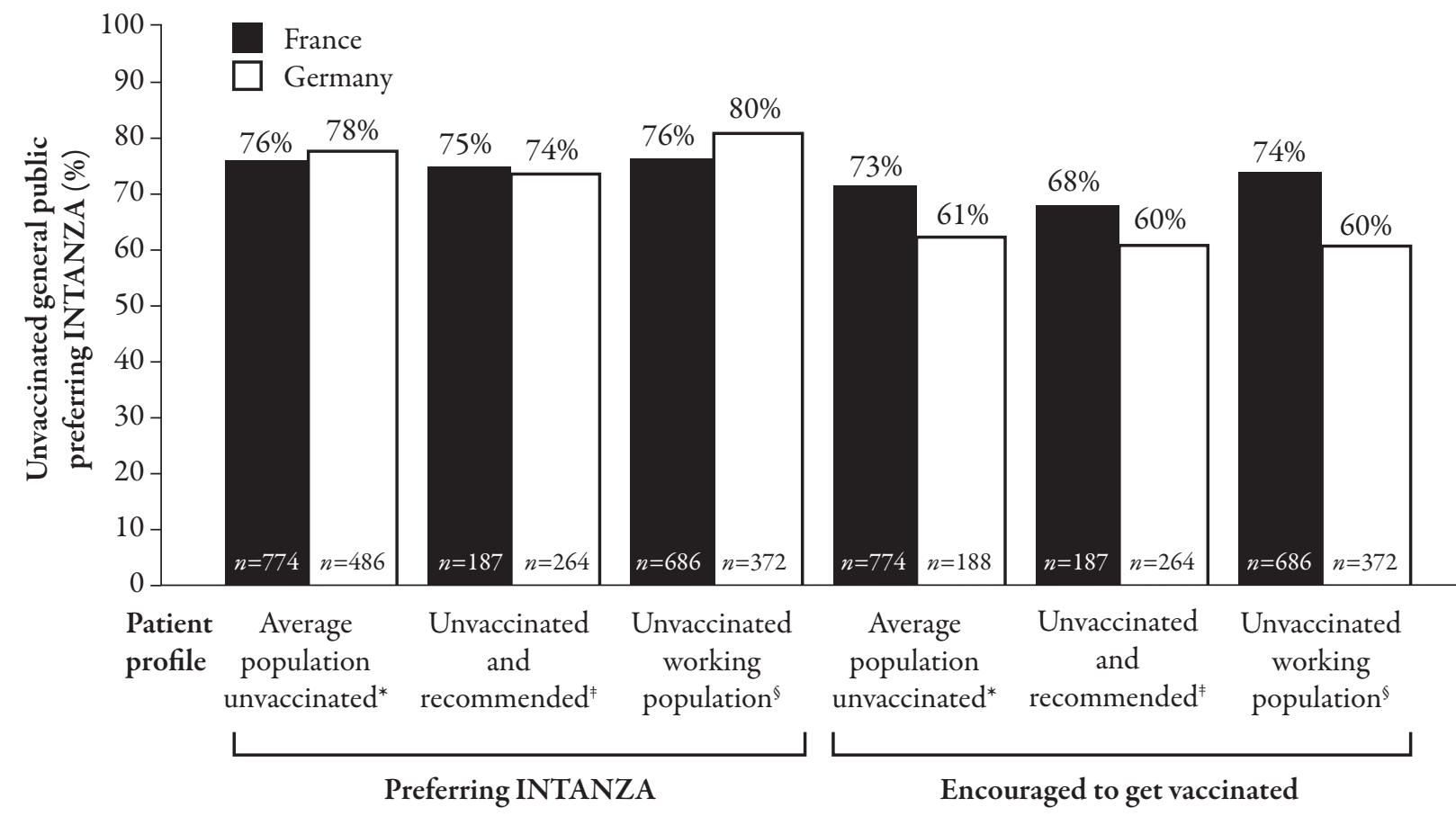

system would reduce their fear: $85 \%$ and $83 \%$ of those participants in France and Germany, respectively, who were averse to needles (average populations: $n=226$ and $n=103$ ).

In addition to those unvaccinated for the previous season, $75 \%$ and $71 \%$ of the average populations who were vaccinated for the previous influenza season in France and Germany, respectively, would prefer to receive INTANZA rather than the conventional IM injection for the next influenza season, if it was recommended by their physician and they were given the choice.

The general public perceived the main benefits of INTANZA to be the small needle size and ID administration (Table 2; as with physicians, members of the general public were free to write their own responses).

\section{DISCUSSION}

These surveys indicate that the availability of INTANZA, the first ID seasonal influenza vaccine to be licensed, would encourage physicians to recommend seasonal influenza vaccination to their patients. Most physicians stated a preference for INTANZA over conventional IM vaccination. Physicians perceived the main benefits of INTANZA to be related to the small/short needle and high immunogenicity of the vaccine. Furthermore, INTANZA is highly acceptable to the general public, and its availability would encourage vaccination, even in those who were not vaccinated for the previous influenza season.

In addition to the well-established patient barriers to seasonal influenza vaccination, 
such as the belief that healthy people do not need vaccinations and family physicians not recommending influenza vaccination, ${ }^{16}$ other barriers relate to the acceptability of the vaccine itself. ${ }^{16-18}$ Indeed, in Europe, 25\% of the elderly expressed concern over the possible side effects of vaccination, ${ }^{17}$ and $14 \%$ stated that they did not like injections or needles. ${ }^{18}$ In the current surveys, $19 \%(n=226)$ of the average general public surveyed in France and 13\% $(n=103)$ of those surveyed in Germany reported being averse to needles.

The results of this survey indicate that INTANZA and its microneedle injection system would increase the uptake of seasonal influenza vaccine by reducing fear of vaccination in the vast majority of those averse to needles. In a European survey across five European countries, $24 \%$ of those surveyed $(n \sim 10,000)$ stated that alternative ways of administration would encourage them to be vaccinated. ${ }^{18}$

The acceptability of ID INTANZA vaccination to the general public seen in these surveys reflects its acceptability in $>5000$ individuals who received ID vaccination with INTANZA in the European phase 3 studies. ${ }^{15}$ In these studies, 2098 individuals aged 18 to 60 years (adults) and 3207 individuals aged $>60$ years (elderly) received INTANZA. Almost all individuals were "very satisfied" or "satisfied" with the ID microneedle injection system (96\% for both adults and elderly), with a vast majority stating that they would "definitely" or "probably" want to be vaccinated using this administration system for the following influenza season ( $85 \%$ of adults and $89 \%$ of the elderly). ${ }^{15}$ Furthermore, the observed reduction in the degree of apprehension with INTANZA compared with IM vaccination also reflects the responses of individuals enrolled in the phase 3 studies. ${ }^{15}$ In these studies, $76 \%$ of adults and $89 \%$ of the elderly stated that they were not at all anxious about receiving INTANZA; 90\% to $91 \%$ of individuals who were vaccinated stated that they were not at all anxious about receiving vaccination the following year. ${ }^{15}$

The results of these surveys indicate that the availability of INTANZA would encourage individuals aged $\geq 50$ years who did not receive seasonal influenza in the previous year to get vaccinated in the future, including those covered by the national agebased recommendations and the workingage population (France: 50-64 years old; Germany: 50-59 years old). Encouraging more individuals covered by national age-based recommendations to have annual seasonal influenza vaccinations would ensure progress towards the achievement of the WHO/EU targets for seasonal influenza vaccination. ${ }^{4,5}$

In addition to the direct healthcare costs associated with seasonal influenza individuals $\geq 50$ years, improving vaccination coverage in this group will reduce lost productivity. Indeed, increasing vaccination coverage has the potential to reduce lost work days. ${ }^{19}$

These surveys have several limitations: the surveys were theoretical, as the participants based their responses on information they received about INTANZA, rather than experience of using or receiving it. A future survey of this nature would be implemented by including groups of participants who had undergone influenza vaccination with INTANZA. The implied improvement in vaccination coverage requires confirmation by investigating prospectively the effect of introducing INTANZA.

\section{CONCLUSION}

In summary, the results of these surveys indicate that ID vaccination with INTANZA is appealing to both physicians and the general public. Most physicians expressed willingness to prescribe 
INTANZA, and the availability of this vaccine would encourage them to recommend seasonal influenza vaccination to their patients. Also, the general public appeared to prefer INTANZA over conventional IM vaccination, with reduced apprehension attributable to the microneedle injection system. The availability of INTANZA would encourage unvaccinated members of the general public, including both the working population and those covered by national agebased recommendations, to be vaccinated. Ultimately, the findings of this study imply that the majority of physicians consider that INTANZA may help progress towards attainment of the $\mathrm{WHO} / \mathrm{EU}$ targets for vaccination coverage.

\section{ACKNOWLEDGMENTS}

This research was sponsored by sanofi pasteur MSD, Lyon, France. The study was administered by GfK SE HealthCare, Nürnberg, Germany. M.F. has cooperated as a speaker on vaccination seminars sponsored by sanofi pasteur MSD $\mathrm{GmbH}$, Leimen, Germany. A.P. is an employee of sanofi pasteur MSD, Lyon, France. T.H. is an employee of GfK SE HealthCare, Nürnberg, Germany. R.A. has declared no conflicts of interest. A.P. is the guarantor for this article, and takes responsibility for the integrity of the work as a whole. All authors contributed to the content of this manuscript and have read and approved the final draft. The authors take full responsibility for the content of this manuscript and thank Communigen Limited, Oxford, UK (supported by sanofi pasteur MSD, Lyon, France) for their assistance in preparing the manuscript.

Open Access. This article is distributed under the terms of the Creative Commons Attribution Noncommercial License which permits any noncommercial use, distribution, and reproduction in any medium, provided the original authors and source are credited.

\section{REFERENCES}

1. World Health Organization. Influenza vaccines. WHO Position Paper. Wkly Epidemiol Rec. 2005;80:279-287.

2. European Centre for Disease Prevention and Control (ECDC). Seasonal influenza and vaccination - the facts. Available at: http://ecdc. europa.eu/en/healthtopics/Documents/0712_ seasonal_human_influenza_vaccination.pdf. Accessed March 21, 2011.

3. Thompson WW, Shay DK, Weintraub E, et al. Mortality associated with influenza and respiratory syncytial virus in the United States. J Am Med Assoc. 2003;289:179-186.

4. World Health Assembly. Fifty-sixth World Health Assembly; Resolution WHA56.19. WHO, Geneva, 2003. Available at: http://www.evm-vaccines.org/ pdfs/wha_resolution_ipd.pdf. Accessed May 4, 2011.

5. European Union. Council recommendation of 22 December 2009 on seasonal influenza vaccination (2009/1019/EU). Off J Eur Union. 2009;348:71-72. Available at: http://eurlex.europa.eu/LexUriServ/ LexUriServ.do?uri=OJ:L:2009:348:0071:0072:EN:P DF. Accessed March 21, 2011.

6. Samson SI, Mégard Y. Overview of vaccination policies for the elderly in Western European countries. Aging Clin Exp Res. 2009;21:210-215.

7. Mereckiene J, Cotter S, D'Ancona F et al. VENICE project gatekeepers group. Differences in national influenza vaccination policies across the European Union, Norway and Iceland 2008-2009. Euro Surveill. 2010;15:pii:19700.

8. Arnou R, Eavis P, Pardo JR, Ambrozaitis A, Kazek MP, Weber F. Immunogenicity, large scale safety and lot consistency of an intradermal influenza vaccine in adults aged 18-60 years: randomized, controlled, phase III trial. Hum Vaccin. 2010;6:346354.

9. Arnou R, Icardi G, De Decker M, et al. Intradermal influenza vaccine for older adults: a randomized controlled multicenter phase III study. Vaccine. 2009;27:7304-7312. 
10. Lambert PH, Laurent PE. Intradermal vaccine delivery: will new delivery systems transform vaccine administration? Vaccine. 2008;26:31973208.

11. Nicolas JF, Guy B. Intradermal, epidermal and transcutaneous vaccination: from immunology to clinical practice. Expert Rev Vaccines. 2008;7:12011214.

12. Atmar RL, Patel SM, Keitel WA. Intanza ${ }^{\circledR}$ : a new intradermal vaccine for seasonal influenza. Expert Rev Vaccines. 2010;9:1399-1409.

13. Nichol KL. The efficacy, effectiveness and costeffectiveness of inactivated influenza virus vaccines. Vaccine. 2003;21:1769-1775.

14. INTANZA $^{\circledR} 9$ and 15 (influenza vaccine injection) product information. France: sanofi pasteur; 2009. Available at: http://www.ema.europa.eu/ docs/en_GB/document_library/EPAR_-_Product_ Information/human/000957/WC500033852.pdf. Accessed March 21, 2011.
15. Reygrobellet C, Viala-Danten M, Meunier J, Weber F, Nguyen VH. Perception and acceptance of intradermal vaccination: patient-reported outcomes from phase 3 clinical trials. Hum Vaccin. 2010;6:336-345.

16. Johnson DR, Nichol KL, Lipczynski K. Barriers to adult immunization. Am J Med. 2008;121:S28-S35.

17. Blank PR, Schwenkglenks M, Szucs TD. Disparities in influenza vaccination coverage rates by target group in five European countries: trends over seven consecutive seasons. Infection. 2009;37:390-400.

18. Blank PR, Schwenkglenks M, Szucs TD. Influenza vaccination coverage rates in five European countries during season 2006/07 and trends over six consecutive seasons. BMC Public Health. 2008;8:272.

19. Aballéa S, Chancellor J, Martin M, et al. The costeffectiveness of influenza vaccination for people aged 50 to 64 years: an international model. Value Health. 2007;10:98-116. 